\title{
HUME JUSNATURALISTA
}

\author{
Maria Isabel Limongi* \\ belimongi@yahoo.com.br
}

RESUMO Trata-se de investigar a relação de Hume com a tradição jusnaturalista moderna, indicando que, sua ênfase na necessidade de um consentimento ou acordo entre os homens como fundamento da propriedade pode ser vista como a reabilitação de uma certa vertente do jusnaturalismo contra aquela que se tornou preponderante a partir de Locke.

Palavras-chave Hume, justiça, propriedade, jusnaturalismo

ABSTRACT This paper aims to investigate the relationship between Hume and the modern tradition of natural law theories, indicating that his emphasis on the need of an accord or agreement as the foundation of property can be seen as the rehabilitation of an aspect of natural law theories against an other, predominant after Locke.

Keywords Hume, justice, property, natural law theories

Em uma nota da Investigação sobre os Princípios da Moral, Hume declara que a sua teoria da propriedade e da justiça "é, no essencial, a mesma sugerida e adotada por Grotius". ${ }^{1}$ Levando em conta que filiar-se a Grotius era uma atitude comum aos membros do que hoje se chama a tradição jusnaturalista moderna, cabe perguntar sobre o que essa afirmação diz da relação de Hume com essa tradição. $\mathrm{O}$ que se segue são algumas notas a esse respeito.

* UFPR. Artigo recebido em 01/12/2011 e aprovado em 30/12/2011.

1 HUME. D. Enquirie concernig the principles of morals, Selby-Bigge (ed.), Oxford: Clarendon Press, 1975, 255.

KRITERION, Belo Horizonte, nº 124, Dez./2011, p. 447-456. 
Comecemos por reconstruir o contexto da afirmação. A nota se dá no apêndide III da Investigação, nomeado "Algumas considerações adicionais concernentes à justiça", cuja intenção, segundo Hume, é a de "fornecer uma explicação mais particularizada da origem e da natureza da justiça, e precisar alguma diferenças entre ela e as outras virtudes." Essas diferenças consistem no caráter artificial da justiça, em contraposição ao caráter natural das outras virtudes, uma distinção fundamental com a qual Hume abre a exposição da teoria da justiça no Tratado (III, 2, 1) e que na Investigação é tratada de forma marginal, no referido apêndide. Da exposição do Tratado, trata-se de reter nesse apêndide que a justiça é uma virtude artificial porque fundada sobre um acordo ou convenção em torno de certas regras de partilha e fixação da propriedade.

Trata-se ainda de mostrar que tipo de acordo ou convenção é esse. Não se trata de um contrato ou promessa, insiste Hume, mas de um "sense of common interest". "Tudo o que é vantajoso para duas ou mais pessoas se todas cumprem a sua parte, mas que perde toda vantagem se apenas uma o faz, não pode provir de nenhum outro princípio". ${ }^{2}$ Sobre a percepção de um interesse comum, fundam-se determinados "esquemas de conduta", ou práticas regulares, isto é, práticas que se fundam e pressupõem a aceitação de determinadas regras gerais de conduta. Hume dá o exemplo da conduta de dois homens que remam conjuntamente um barco ou que partilham de uma linguagem comum.

É nesse momento do texto, quando está dizendo que as regras de justiça consistem em práticas dessa natureza, que Hume puxa a nota sobre Grotius para dizer que "essa teoria relativa à origem da propriedade, e consequentemente da justiça, é, no essencial, a mesma sugerida e adotada por Grotius." Segue-se então a citação de um longo trecho do De jure belli ac pacis (livro II, cap. 2, \# 4 e 5), no qual Grotius afirma basicamente duas coisas.

Em primeiro lugar, que a origem da propriedade está num consentimento - um consentimento que toma primeiramente a forma de um acordo explícito quanto à divisão dos bens e da terra, e depois, a de um acordo tácito quanto ao direito do primeiro ocupante em relação ao que não foi dividido no primeiro acordo. Trata-se assim de uma passagem em que Grotius frisa o caráter acordado ou convencional da propriedade (e, portanto, da justiça, pensada por ele em termos de relações de propriedade). 
Grotius afirma ainda na passagem citada por Hume que esse consentimento se dá num momento em que os bens não podiam mais ser usados em comum, em virtude do incremento das artes e da divisão do trabalho, de um lado, e de um certo "defeito na equidade e no amor" dos homens (da ambição e da inveja), do outro. Trata-se assim de uma passagem em que Grotius afirma o caráter histórico e adventício da propriedade, em função de certas mudanças na condição de vida dos homens, que tornaram inviável a comunidade original dos bens.

Ao filiar-se a Grotius, num contexto em que o que está em foco é o caráter artificial da justiça, Hume parece querer dizer que a afirmação de que a justiça é uma virtude artificial deve ser entendida no duplo sentido afirmado por Grotius na passagem citada: a justiça é artificial porque (1) repousa sobre um acordo explícito ou tácito acerca da propriedade e (2) porque é instituída pelos homens, ao longo de uma história.

O ponto 2, a ideia de que a justiça tem uma história, sendo uma aquisição do homem, que a constrói por etapas, em resposta às mudanças advindas nas condições de sua existência, é um traço geral, unificador de boa parte da tradição jusnaturalista moderna. Como argumenta Buckle, Hutcheson e Hume são continuadores dessa tradição (Buckle se refere, mais especificamente, a Grotius, Pufendorf e Locke), na medida em que pensam as "relações de propriedade enquanto respostas naturais a mudanças nas circunstâncias humanas, em função da crescente sofisticação da vida social". ${ }^{3}$

Ao focar Hume e Hutcheson sobre o pano de fundo da tradição jusnaturalista Buckle declara-se seguidor de Forbes, que já argumentara nos dois primeiros capítulos de seu Hume's philosophical politics que o método experimental anunciado por Hume no sub-título do Tratado está em fio de continuidade com um certo modo de investigação empírica e histórica sobre a lei natural posta em marcha por Grotius. Tal método consiste em retirar os princípios da lei natural de uma investigação sobre a natureza humana e de suas tendências para a vida social. Todos esses autores (a lista de Forbes é Grotius, Pufendorf, Cumberland e Hutcheson) pensam "a propriedade, os contratos e promessas, a sociedade civil e o governo como invenções humanas que aparecem enquanto e quando são requeridas para satisfazer a necessidade do animal social que o homem nunca deixou de ser." ${ }^{4} \mathrm{~A}$ ideia fundamental

3 BUCKLE, S. Natural Law and the Theory of Property. Grotius to Hume. Oxford: Clarendon Press, 1991, prefácio, vii.

4 FORBES, D. Hume's philosophical politics, Cambridge: Cambridge University Press, 1975, p. 27. 
que os une numa única tradição é a de que essas instituições se dão em um processo (e não por um único ato).

A tese de que a teoria da justiça de Hume está em fio de continuidade com a tradição jusnaturalista moderna é ainda retomada por Haakonssen, para quem "boa parte da filosofia moral do século XVIII foi profundamente influenciada pelo desenvolvimento de teorias da lei natural no seio do protestantismo a partir de Hugo Grotius." 5 há vários outros estudos que exploram essa relação - uma relação inegável, da qual Hume se mostra ciente e cioso em sua nota sobre Grotius.

No entanto, como mostrou Tuck ${ }^{6}$, essa tradição está longe de ser perfeitamente homogênea. Segundo Tuck, Grotius foi apropriado de diversos modos, nem sempre convergentes sobre certos pontos fundamentais. Há a apropriação feita por Selden e Hobbes e a apropriação feita pelos radicais ingleses - ambas as quais tomam o direito como uma liberdade fundamental, a ser limitada por atos voluntários, através dos quais essa liberdade se exerce. E há, por outro lado, a apropriação feita por Pufendorf, Cumberland e Locke, que já não tomam o direito como uma liberdade fundamental, mas como algo que pode ser perfeitamente traduzido em termos de um conjunto de deveres.

É emblemática desta última tendência a observação de Pufendorf em De jure naturae et gentium, III, 5, 3, segundo a qual nem todo poder de fazer algo é um direito, mas apenas aqueles que produzem um efeito moral nos outros, ou seja, uma obrigação. Sendo assim, argumenta Tuck, para Pufendorf, como também para Cumberland e Locke, o direito já não é primeiro e fundamental e não estamos mais diante de uma teoria do direito propriamente dito, mas antes, da lei natural. A ênfase recai sobre a lei. Segundo Haarkonsen, Hume e Adam Smith seriam exceções ao modo como o main stream da filosofia escocesa se apropriou do jusnaturalismo (justamente como um teoria da lei natural), na medida em que suas ênfases voltam a recair sobre os direitos. Haarkonsen reconhece, porém, a dificuldade em sustentar essa afirmação no que diz respeito a Hume, já que este, em nenhum momento, fala em direitos.

Seja como for, o fato é que esse caráter equívoco e multi-facetado da tradição jusnaturalista moderna implica cautela na compreensão da menção de Hume a Grotius. Não há dúvida de que Hume seja seguidor de Grotius, porque como ele e outros, tais como Hutcheson e Locke, Hume entende que a

5 HAAKONSSEN. K. Natural Law and moral philosophy, from Grotius to scottish enlightment, Cambridge University Press, 1996, p. 1.

6 TUCK, R. Natural rights theories, their origin and development, Cambridge University Press, $1979\left(1^{\circ}\right.$ edição), 1995. 
propriedade se forma historicamente enquanto uma resposta a mudanças nas circunstâncias da vida humana. Mas há tensões importantes que não podem passar despercebidas nessa auto-filiação à tradição jusnaturalista. Na passagem de Grotius citada por Hume, como vimos, Grotius não apenas afirma que a propriedade é histórica, mas que ela se funda sobre atos de consentimento explícitos e tácitos. Ora, esse é um ponto enfaticamente negado por Locke, contra Grotius e Pufendorf.

Como se sabe, é um ponto central no argumento de Locke no famoso capítulo V do segundo Tratado que as relações de propriedade são estabelecidas pelo trabalho, sem que para isso se requeira "nenhum pacto expresso por parte de todos os homens." 7 Com respeito a essa afirmação, uma nota de Laslett, na sua edição do segundo Tratado, nos adverte que ela

confirma que o presente parágrafo e todo o capítulo sobre a propriedade foram escritos tendo Locke as obras de Filmer em mente e com vistas a uma refutação cabal delas. Isso porque foi Filmer quem levantou a dificuldade de que o comunismo original não poderia dar lugar à propriedade privada sem o consentimento universal da humanidade. ${ }^{8}$

Com efeito, a tese de que o trabalho gera propriedade sem consentimento pode ser vista como uma estratégia para driblar a dificuldade que Filmer levantara contra Grotius, quanto ao modo como este último pensou o processo de constituição da propriedade a partir da comunidade original dos bens. Grotius faz depender esse processo de um consentimento dos homens, ainda que tácito, em relação ao ato de apropriação. Filmer objeta, que, sendo assim, bastaria que um só homem não consentisse com a apropriação para que ela se tornasse ilegítima. Como mostra Buckle ${ }^{9}$, a objeção não é boa e Grotius teria como respondê-la. Locke, porém, parece tê-la levado a sério, procurando colocar a questão fora de controvérsia. Ele o faz, afirmando que a propriedade, sendo gerada pelo trabalho, independe do consentimento.

Esta afirmação fez seguidores. Lendo Grotius e Pufendorf a partir de Locke, Barbeirac acrescenta notas às famosas edições de suas obras, contestando-os sobre esse aspecto. Segundo Barbeirac, em nota à mesma passagem de Grotius citada por Hume, "não há necessidade de um contrato para fundar o direito

7 LOCKE, J. Dois tratados sobre o governo, São Paulo: Martins Fontes, 2005, \#26.

8 LOCKE, J. Op. cit., p. 406.

9 BUCKLE, S. op. cit., cap. 3 (3.2), p. 161 e ss, onde se reconstitui a crítica de Filmer a Grotius e se retoma a posição de Laslett segundo a qual a tese lockiana de que a propriedade independe do consentimento se reporta a essa crítica. 
da primeira ocupação." ${ }^{10} \mathrm{Na}$ mesma linha segue Hutcheson, ao insistir que a comunidade natural dos bens é negativa, o que quer dizer que "no princípio qualquer um podia com justiça ocupar o que quisesse, sem consultar o resto da humanidade, não sendo preciso recorrer a nenhuma antiga convenção dos homens para explicar a introdução da propriedade."

Assim, quando Hume cita Grotius precisamente nessa passagem em que Grotius está afirmando que a propriedade funda-se sobre um consentimento, ele certamente sabe que está tocando num ponto polêmico e que a filiação a Grotius não quer dizer apenas concordância com a tradição por ele inaugurada, mas também discordância com relação a certos rumos tomados por essa tradição - o que nos conduz ao conteúdo de uma segunda nota de Hume, desta vez ao Tratado da Natureza Humana III, 2, 4, em que ele se refere à teoria da propriedade de Locke.

O contexto da nota é o da explicação de como os homens chegam a estabelecer regras gerais de partilha da propriedade. Não basta, segundo Hume, que os homens reconheçam a utilidade social das regras de estabilização da posse, das quais derivam a propriedade. É preciso que a regra geral "que a posse deva ser estável"12, estabelecida pelo interesse comum, seja aplicada aos casos particulares, ou seja, é preciso que haja regras menos gerais, determinando quais bens pertencem a quem. Tal regra é, num primeiro momento, a regra da ocupação imediata. "Deve imediatamente ocorrer, como o mais natural expediente, que cada um continue a gozar daquilo de que no presente é senhor." 13 Pressionados pela necessidade de haver uma regra que evite a "violência e a desordem", os homens concordam em adotar essa regra (agree in prefering it (T 504)), na medida em que ela é natural, chegando em seguida, pelo mesmo caminho, "by universal agreement, express or tacit ( $\mathrm{T}$ 505)", à regra da primeira ocupação. A ênfase no consentimento é fundamental na medida em que nos remete ao conteúdo da nota sobre Grotius e é tão mais relevante uma vez que é nesse exato momento que Hume introduz a nota contra Locke e seus seguidores.

Alguns filósofos, diz a nota, explicam o direito (right) de ocupação dizendo que "cada um tem a propriedade em seu trabalho" e que, quando se acrescenta algo a alguma coisa pelo trabalho, isso gera a propriedade sobre a coisa. Mas, contesta Hume, em primeiro lugar, há muitas formas de ocupação,

10 Cf. GROTIUS, The rights of war and peace, Liberty Fund, 2005, II, 2, \#5, p. 427

11 HUTCHESON $A$ short introdution to moral philosophy In. Collected works of F. Hutcheson, vol. IV. Hildesheim/ Zurich/ New York: G. Olms Verlag, 1990, livro II, cap. 6, p. 159

12 HUME. D. A Treatise on Human Nature, Selby-Bigge/ Nidditch (eds), Oxford: Clarendon Press, $1989,502$. 13 Idem, 503. 
das quais não se pode dizer que se acrescentou algo àquilo que por meio dela se adquire, como quando se possui um campo pelo fato do seu gado pastar nele. Ou seja, que propriedade o trabalho gera e que trabalho gera propriedade são questões que estão longe de ser incontroversas, como supõe Locke.

A tese de que o trabalho constitui propriedade não é aceitável, em segundo lugar, porque é um modo de explicar a propriedade pela acessão (por acréscimo a algo que já se possui), o que, por sua vez, pressupõe a propriedade. Ou seja, a propriedade dos bens exteriores está pressuposta na forma da propriedade à própria pessoa, que é suposta e não explicada. E, por fim, não se pode dizer que o trabalho acrescenta alguma coisa a um objeto senão em sentido figurado. $\mathrm{O}$ trabalho apenas altera o objeto, uma alteração absolutamente relevante, porque por meio dela se estabelece uma relação entre nós e os objetos sobre a qual se fundará a propriedade, mas insuficiente por si só para introduzi-la. Antes, a propriedade se explica "de acordo com os princípios precedentes", ou seja, a partir de um consentimento em torno de uma regra sugerida por essa relação - a regra de que a posse gera propriedade, isto é, direito à posse. Hume está assim enfatizando que apenas o consentimento pode explicar a propriedade ou o direito à posse, por mais naturalmente que se imponha a nós a regra sobre a qual se irá consentir (a saber, que cada um tem direito ao que possui).

Sobre a questão do consentimento e toda a polêmica em torno dela, Tuck faz algumas observações que merecem menção. Ele chama a atenção, em primeiro lugar, para o fato de que a tese de que a propriedade funda-se sobre um consentimento, expressa na passagem do De jure belli ac pacis citada por Hume, não foi sempre a posição de Grotius, que defendia em suas primeiras obras a ideia de que há direito de propriedade no estado de natureza independentemente de qualquer consentimento. Ou seja, a posição de Grotius é ambígua quanto a esse ponto. Tuck observa, além disso, que a ênfase de Pufendorf no consentimento vai contra a teoria do direito inaugurada por Grotius e desenvovida por Selden e Hobbes. Pufendorf, querendo refutar Hobbes, teria jogado o bebê junto com a água do banho - Grotius e os direitos -, uma vez que, se todo direito depende de um acordo sobre a sua utilidade geral, então, não há mais direitos fundamentais. ${ }^{14}$

Ainda segundo Tuck, na Inglaterra, com Hale e Cumberland e, de maneira mais radical, com Locke, desenvolveu-se ainda um outro tipo de recusa a Hobbes e à vertente absolutista do jusnaturalismo, que passou pela reabilitação do primeiro Grotius, para quem o direito à propriedade não depende de 
consentimento. Não haveria propriamente incompatibilidade entre o primeiro Grotius e o de De jure belli ac pacis, se tomarmos o consentimento de que ele nos fala nessa última obra como um consentimento tácito, não contratual. De fato, nota Tuck, Cumberland também fala em consentimento, mas de um consentimento tácito, e a questão central para Locke não está tanto em negar o consentimento em torno da propriedade, mas, mais especificamente, em negar que ela dependa de um consentimento explícito, ou seja, contratual. Como isso é também negado pelo "consentimento natural" de que nos fala Hume, as observações de Tuck podem significar que Hume, no lugar de se afastar, acompanha de perto esse movimento de reabilitação tipicamente britânico de Grotius contra Hobbes, a que ele se refere, do qual Locke seria o principal representante. Mas, se é assim, como entender a ênfase de Hume nas duas notas a que nos referimos acima (uma das quais claramente anti-lockiana) na necessidade e no papel do consentimento para a introdução da propriedade?

A questão é tão mais importante porque ela está no cerne da definição da justiça como virtude artificial, que faz o contexto da nota de Hume sobre Grotius. Sabemos que essa tese gerou controvérsias e que Hume teve que se explicar sobre ela, quando uma lista de proposições tidas como perigosas a ele atribuídas circulou em campanha contra a sua candidatura à cadeira de filosofia moral de Edimburgo. Dentre as acusações, há a taxação de "hobbismo". Hume seria ainda pior do que Hobbes, segundo o autor do panfleto, por ter abolido todas as obrigações naturais, até mesmo a obrigação de fazer contratos e pactos, que Hobbes ainda reconheceria como uma obrigação natural. Hume respondeu a essa acusação em sua Letter from a gentleman (a partir da qual conhecemos também o conteúdo das acusações) e é provável que a sua nota de filiação a Grotius na Investigação faça parte de uma tentativa de se livrar dessa pecha. De fato, como insiste Buckle, a tese da artificialidade da justiça é perfeitamente compatível com a tradição jusnaturalista que passa por Hutchesom e Locke, para a qual a justiça repousa, não sobre atos contratuais, mas sobre um progressivo fazer humano.

Toda a questão reside em saber no que consiste essa história da propriedade e esse progressivo fazer, já que, quanto ao modo de concebêlo, Hume parece se singularizar não apenas diante de Locke, mas de toda a tradição jusnaturalista moderna. É um traço dessa tradição, acentuado por Pufendorf e Locke, a atribuição de um certo caráter dedutivo e necessário às relações morais. Para Pufendorf e Locke, a história que realiza o direito, o realiza na medida em que reafirma nas diversas circunstâncias históricas as mesmas relações lógicas e a-históricas em que o direito consiste. É assim que, no caso de Locke, a relação entre pessoa, trabalho e propriedade funda a 
propriedade de diferentes maneiras nos diversos momentos da história, de tal forma que o que em certo momento não constitui propriedade (por exemplo, o excesso de produção), em outro (depois da invenção da moeda) constitui. A invenção da moeda, ao permitir dar uso ao excesso de produção, torna legítima a apropriação ampliada e desigual. Contudo, o que legitima a apropriação ampliada é a relação entre pessoa, trabalho e propriedade, que permanece a mesma nas novas circunstâncias.

Para Hume, no entanto, não há uma relação lógica e necessária na base da história da justiça. Não há uma regra natural no sentido de uma lei a-histórica a ser reconhecida pela razão, a partir da qual se possa medir os acontecimentos históricos e as práticas humanas concernentes às relações de propriedade. A regra é sempre histórica, fundada sobre práticas humanas acordadas. A justiça é uma instituição social e tudo o que a natureza fornece são os princípios ou causas gerais que explicam essa instituição, no que ela tem de regular.

Para ser breve, o que parece haver de singularmente importante no jusnaturalismo de Hume é que para ele a justiça se impõe por ser útil à sociedade, sendo a utilidade a sua única medida. Grotius recusa a ideia de que a utilidade é a mãe da justiça, ainda que, como salienta Buckle ${ }^{15}$, afirme não haver incompatibilidade entre justiça e utilidade, como, aliás também Cícero no Dos Deveres, ao articular o útil e o honesto. Mas, nesse esquema, a utilidade não é $a$ medida da justiça, e sim a natureza, a ordem das coisas. Essa ideia parece sobreviver no jusnaturalismo moderno, mas não no de Hume, que faz da utilidade a única fonte da justiça.

Mais precisamente, certas regras de partilha da propriedade se impõem porque são percebidas como úteis para a sociedade, sendo essa percepção o que nos motiva a respeitá-las. Esse ponto é fundamental: a utilidade não se afirma do ponto de vista de uma ordem dada ou providencial do mundo, mas é algo de que os homens têm que se convencer para que possam se obrigar diante da justiça e, nessa medida, criá-la. Essa é uma tese fundamental de Hume com relação a todas as virtudes que não apenas à justiça: a virtude não é outra coisa senão o que é considerado virtuoso, ou seja, nada além de opinião, uma opinião que é sempre histórica, porque formada no processo pelo qual se afere a posteriori os efeitos das ações. Assim, não há medida natural, no sentido de um padrão a-histórico e independentemente da ação humana, da justiça. A justiça é uma prática social, sustentada pela opinião dos homens de que essa prática é socialmente vantajosa. Eis o que o autor do 
panfleto contra Hume deve ter pressentido como algo perigosamente distante da cartilha jusnaturalista.

Diante dessa desconfiança, Hume se defende acentuando sua filiação à tradição. Grotius já não dizia que a justiça é uma instituição humana, em resposta a mudanças advindas nas circunstâncias em que se tecem às relações sociais, de maneira a assegurar e fortalecer os vínculos sociais? Sim, mas para Grotius a justiça não é apenas uma instituição, mas uma instituição que responde a certas relações naturalmente dadas entre pessoa e propriedade. Esse ponto que interessava a Locke, Barbeirac e outros frisar, Hume nega (de maneira aliás bastante minuciosa e detalhada nas longas notas do Tratado, em que procura mostrar que a propriedade não é algo real nas coisas) para reter do jusnaturalismo de Grotius a ideia de que a justiça funda-se sobre um acordo utilitário.

\section{Referências bibliográficas}

BUCKLE, S. Natural Law and the Theory of Property. Grotius to Hume. Oxford: Clarendon Press, 1991.

FORBES, D. Hume's philosophical politics, Cambridge: Cambridge University Press, 1975.

GROTIUS, The rights of war and peace, Liberty Fund, 2005.

HAAKONSSEN. K. Natural Law and moral philosophy, from Grotius to scottish enlightment, Cambridge: University Press, 1996.

HUME. D. Enquirie concernig the principles of morals, Selby-Bigge (ed.), Oxford: Clarendon Press, 1975.

A Treatise on Human Nature, Selby-Bigge/ Nidditch (eds), Oxford:

Clarendon Press, 1989.

HUTCHESON A short introduction to moral philosophy, In, Collected works of F. Hutcheson, vol. IV. Hildesheim/ Zurich/ New York: G. Olms Verlag, 1990.

LOCKE, J. Dois tratados sobre o governo, São Paulo: Martins Fontes, 2005.

TUCK, R. Natural rights theories, their origin and development, Cambridge: University Press, 1979 (1ª edição), 1995. 